\title{
From Here to There: Vision, Value, and the Advancement of Respiratory Care
}

The GPS app on my smartphone was on, and my destination loaded. I was on my way. I knew where I was going and I knew the general direction I would have to travel, but I had a number of options concerning the route. Since I didn't know which one would be best, I was content to leave that decision up to the voice my family calls "Penelope." She would get me "from here to there." Penelope has an impeccable sense of direction and an unlimited supply of data that helps me avoid most of the detours and delays along the way. She can direct the route for the shortest distance traveled and amount of time required to reach almost any destination.

I wish navigating the future of respiratory care was as easy. We know the general direction of our profession, and our national organizations are working together to lead the way. However, it's the dimly lit fog of strategies, initiatives, procedural steps, and ever-evolving challenges within the current climate and culture of health care that will slow us down. As they say, the devil is in the details. That's why moving our profession from here to there will require influential practitioners who can articulate the collective vision for respiratory care and demonstrate the value of our profession in whatever practice settings they encounter. In this issue of RESPIRATORY CARE, the article by Robert Dailey et al ${ }^{1}$ illustrates how respiratory therapists can bring value to the bedside and advance the profession within their sphere of influence.

\section{Vision}

Leadership is not fully defined by position or status alone. John Maxwell states, "The only thing a title can buy is a little time- either to increase your level of influence with others or to undermine it."2 May I suggest the same is true with a credential? Credentials provide an opportunity to practice, but it's our responsibility to maintain credibility, grow as

Mr Jones has disclosed no conflicts of interest.

Correspondence: Thomas D Jones MEd RRT CPFT, College of Health Professions, University of Arkansas for Medical Sciences, 4301 West Markham Street Slot \#737, Little Rock, AR 72205-7199. E-mail: tjones@4uams.edu.

DOI: $10.4187 /$ respcare. 05576 professionals, and continue moving respiratory care forward as a respected and essential partner in health care. In its most basic form, leadership is influence. ${ }^{3}$ By that definition, anyone can be a leader-since anyone can have influenceeither from the front or from within a team. However, the

\section{See the Original Study on Page 517}

element that makes leadership effective is vision. Vision is the "there" in the from here to there. It's a picture of what our profession could be and should be. Without a clearly communicated "there" in mind, travelers have no sense of direction and often find themselves lost along the way.

A common, coherent vision creates an environment in which well-conceived strategies can be formed and implemented. In the pursuit of the vision, both the responsibilities and the successes can be shared, ${ }^{4}$ which strengthens organizational and professional standing. Shared vision within a profession can promote intellectual curiosity and creativity-exactly what is needed to address the shifting health-care challenges in general and respiratory care practice in particular. ${ }^{5}$ For many years the American Association for Respiratory Care, Committee on Accreditation for Respiratory Care, National Board for Respiratory Care, and other organizational leaders in respiratory care have been trying to communicate a unifying picture for the profession. "Creating a Vision for Respiratory Care in 2015 and Beyond," 6 along with the associated conferences on the competencies needed for future practice ${ }^{7}$ and how the workforce will need to transform for maximum effectiveness, ${ }^{8}$ attempt to bring a sharper focus to that vision.

Undoubtedly, respiratory care needs strong influencers nationally. Equally as important, we need them locally. It is the respiratory therapists at the bedside, in the clinic, in front of the classroom, at the research table, on the discharge planning team, and in every arena of practiceinside and outside of the hospital — who must embrace the shared vision and extend the profession to its broadest circumference. Vision energizes practitioners to question ideas, gives them the courage to pursue answers to questions, and motivates them to see evidence-based strategies through to implementation. It's this type of common, vision-driven influence that will shape our future and define our value. 


\section{EDITORIALS}

\section{Value}

In the ever-changing milieu of health care, the challenges have never been greater. The shifting paradigms of payment systems-from traditional fee-for-service reimbursement models to outcomes-based care and collective accountability - have turned the financial management of health care upside down. ${ }^{9}$ Even more difficult for practitioners to embrace may be the challenges of redesigning practice from a therapy-driven model of care to a holistic, patient-centered model that focuses on patient outcomes, disease management, interprofessional care coordination, and evidence-based scholarship and practice. These are the arenas where respiratory therapists can have the greatest, most immediate impact. Every hospital is focused like a laser beam on improving patient safety, reducing readmissions, minimizing risk, and lowering costs. In some ways, these objectives are more valuable than generating revenue because they increase the overall margin without consuming resources. When respiratory therapists implement strategies, such as those offered by Dailey et al, ${ }^{1}$ that effectively and consistently contribute to these objectives, we add value to the organization and solidify our position as an economic partner in optimizing the margin (ie, more than an expensive cost center).

Additionally, value should imply more than cost reduction or financial benefit to an institution. It is also created by giving exceptional quality and making a significant impact on the overall patient experience and outcome. ${ }^{10}$ Whether it's in clinical practice in the medical center ICU, chronic disease management in a regional hospital, tobacco cessation at a community center, or initiatives in clinical research, practitioners of influence and vision must advance the profession in an ever-widening scope and diversity of practice to treat the substantial number of patients with acute and chronic cardiopulmonary disorders. In doing so, we demonstrate our ability to improve the overall health of our patients and communities.

There is ample and growing evidence that respiratory therapists are in an enviable position to contribute value to health-care delivery in a variety of ways, including patient-centered protocols, ${ }^{11}$ disease management, ${ }^{12,13}$ telehealth ${ }^{14}$ and discharge planning, ${ }^{15}$ to name just a few. The article by Dailey et al $^{1}$ illustrates the value respiratory therapists can have in the expansion of respiratory care and the immediate impact they can have on patient care. The ripple effect these kinds of interventions have on health care ultimately extends beyond simple patient outcomes to work flows and processes in the continuity of care for the patient, efficiency within the organization, and cost reduction. That's demonstrated value and the practical benefit of scholarly activity conducted by practicing therapists. The article validates the kind of front line innovation necessary for the effectiveness of respiratory care at a local level, where therapists are searching for ways to utilize their professional influence and tackle the tough questions that impact their practice setting.

\section{Advancement}

The respiratory therapist is a unique, strong, and capable resource at the very center of the crossroads in health care. The direction our profession ultimately takes will be determined by the willingness of therapists to embrace the opportunities facing them and their attempts to make their own unique contributions to the strength and scope of their practice. The benefit of the protocols, initiatives, and strategies we can bring to the table are not of exclusive interest to the therapist: They can be appreciated and implemented by practitioners in a wide variety of disciplines. The ultimate significance of our involvement is that it strengthens our standing and contribution as a valuable partner in the interprofessional team setting.

Practitioners strongly desire professional growth and the opportunity to expand their practice, including reimbursement for services. ${ }^{16}$ The identified core competencies of technical proficiency, interprofessional practice, communication, critical thinking, and professionalism are vital elements of the foundational underpinning for the strategies that will move us in that direction. ${ }^{5}$ The expanding vision for baccalaureate entry level, master's degree practice, or an advanced practice respiratory therapist should not be ignored or discounted as out of touch or out of reach. Neither should the value of evidence-based scholarship — when it is initiated and conducted by therapists who are curious, courageous, and committed to widening the scope of our profession-be underestimated. Such internal leadership and vision should be encouraged and supported at every opportunity. ${ }^{17}$

There is no doubt the journey from here to there will continue to be full of unexpected twists, turns, and challenges. Failure to prioritize value and move our profession forward will haunt us, perhaps sooner rather than later. Nevertheless, I am convinced the next decade can be marked with considerable progress in research, improvements in clinical practice, and breakthroughs for our profession. That can be our "there" if every therapist will embrace the shared vision, take responsibility for his or her corner of the profession, and become a practitioner of influence who can articulate who we are and the unique contribution we bring to the health-care team.

Thomas D Jones MEd RRT CPFT

Associate Chair and Program Director Cardio-Respiratory Care Program College of Health Professions University of Arkansas for Medical Sciences Little Rock, Arkansas 


\section{EDITORIALS}

\section{REFERENCES}

1. Dailey RT, Malinowski T. Baugher M. Rowley DD. Impact of a respiratory therapy assess-and-treat protocol on adult cardiothoracic ICU readmissions. Respir Care 2017;62(5):517-523.

2. Maxwell JC. The 21 indispensable qualities of a leader: becoming the person that people will want to follow. Nashville, Tennessee:: T. Nelson;1999: 13.

3. Kruse K. What is leadership? Forbes Magazine. April 9, 2013. https: //www.forbes.com/sites/kevinkruse/2013/04/09/what-is-leadership/\# 36c63efc5b90. Accessed March 31, 2017.

4. Zeitchik S. 10 ways to define leadership. Business News Daily 2012. http://www.businessnewsdaily.com/3647-leadership-definition.html. Accessed February 10, 2017.

5. Myers TR. Thinking outside the box: moving the respiratory care profession beyond the hospital walls (editorial). Respir Care 2013; 58(8): 1377-1385.

6. Kacmarek RM, Durbin CG Jr, Barnes TA, Kageler WV, Walton JR, O'Neil EH. Creating a vision for respiratory care in 2015 and beyond. Respir Care 2009;54(3):375-389.

7. Barnes TA, Gale DD, Kacmarek RM, Kageler WV. Competencies needed by graduate respiratory therapists in 2015 and beyond. Respir Care 2010;55(5):601-616.

8. Barnes TA, Kacmarek RM, Kageler WV, Morris MJ, Durbin CG Jr. Transitioning the respiratory therapy workforce for 2015 and beyond. Respir Care 2011;56(5):681-690.

9. Latkovic T. The trillion dollar prize using outcomes-based payment to address the US healthcare financing crisis. http://healthcare. mckinsey.com/sites/default/files/the-trillion-dollar-prize.pdf. Accessed February 10, 2017.

10. Porter ME. What is value in health care? N Engl J Med 2010; 363(26):2477-2481.

11. Kollef MH, Shapiro SD, Clinkscale D, Cracchiolo L, Clayton D, Wilner R, Hossin L. The effect of respiratory therapist-initiated treatment protocols on patient outcomes and resource utilization. Chest 2000;117(2):467-475.

12. Peytremann-Bridevaux I, Staeger P, Bridevaux PO, Ghali WA, Burnand, B. Effectiveness of chronic obstructive pulmonary diseasemanagement programs: systematic review and meta-analysis. Am J Med 2008;121(5):433-443.e4.

13. Silver PC, Kollef MH, Clinkscale D, Watts P, Kidder R, Eads B, et al. A respiratory therapist disease management program for subjects hospitalized with COPD. Respir Care 2017;62(1):1-9.

14. Polisena J, Tran K, Cimon K, Hutton B, McGill S, Palmer K, Scott RE. Home telehealth for chronic obstructive pulmonary disease: a systematic review and meta-analysis. J Telemed Telecare 2010;16(3): 120-127.

15. Tearl DK, and Hertzog JH. Home discharge of technology-dependent children: evaluation of a respiratory-therapist driven family education program. Respir Care 2007;52(2):171-176.

16. Smith SG, Endee LM, Benz Scott LA, Linden PL. The future of respiratory care: results of a new york state survey of respiratory therapists. Respir Care 2017;62(3):279-287.

17. Martins C, and Kenaszchuk C. Research capacity of respiratory therapists: a survey of views, opinions and barriers. Can J Respir Ther 2013;49(4):15-19. 